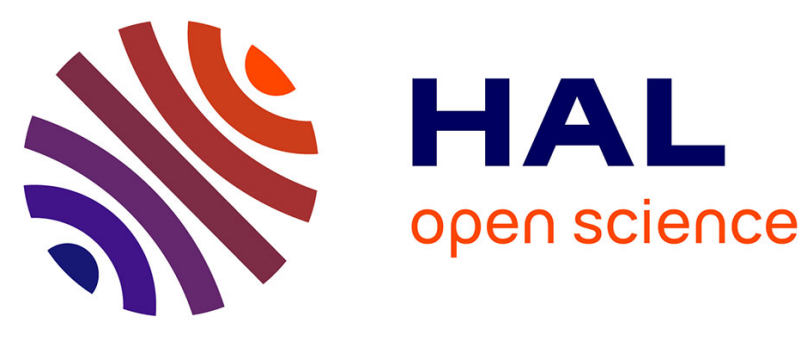

\title{
Rationale for Therapeutic Drug Monitoring of Biopharmaceuticals in Inflammatory Diseases
}

Gilles Paintaud, Christophe Passot, David Ternant, Antonio Bertolotto, Theodora Bejan-Angoulvant, Dora Pascual-Salcedo, Denis Mulleman

\section{To cite this version:}

Gilles Paintaud, Christophe Passot, David Ternant, Antonio Bertolotto, Theodora Bejan-Angoulvant, et al.. Rationale for Therapeutic Drug Monitoring of Biopharmaceuticals in Inflammatory Diseases. Therapeutic Drug Monitoring, 2017, 39 (4), pp.339-343. 10.1097/FTD.0000000000000410 . hal02794099

\section{HAL Id: hal-02794099 \\ https://hal.science/hal-02794099}

Submitted on 5 Jun 2020

HAL is a multi-disciplinary open access archive for the deposit and dissemination of scientific research documents, whether they are published or not. The documents may come from teaching and research institutions in France or abroad, or from public or private research centers.
L'archive ouverte pluridisciplinaire HAL, est destinée au dépôt et à la diffusion de documents scientifiques de niveau recherche, publiés ou non, émanant des établissements d'enseignement et de recherche français ou étrangers, des laboratoires publics ou privés. 
Rationale for therapeutic drug monitoring of biopharmaceuticals in inflammatory diseases

Gilles Paintaud ${ }^{\text {aft }}$, Christophe Passot ${ }^{\mathrm{a}}$, David Ternant ${ }^{\mathrm{a}}$, Bertolotto Antonio ${ }^{\mathrm{b}}$, Theodora Bejan-Angoulvant ${ }^{\mathrm{a}}$, Dora Pascual-Salcedo ${ }^{\mathrm{c}}$, Denis Mulleman ${ }^{\mathrm{a}}$

\#corresponding author

Institutions:

a) Université François-Rabelais de Tours, CNRS UMR 7292, France

b) Neurologia 2, Centro Riferimento Regionale Sclerosi Multipla (CReSM) \& Neuroscience Institute Cavalieri Ottolenghi (NICO), San Luigi Hospital, Orbassano, Turin, Italy

c) La Paz University Hospital, Madrid, Spain

\section{Corresponding author:}

Prof. Gilles Paintaud: GICC - UMR 7292, UFR de Médecine, Bâtiment Vialle, 10 boulevard Tonnellé, BP 3223, 37032 Tours Cedex 01. Tel.: +33 247366 079; Fax: +33 247366 125. Email address: paintaud@med.univ-tours.fr

\section{Competing interests}

GP reports grants received by his research team from Novartis, Roche Pharma, Genzyme, MSD, Chugai, and Pfizer, outside of the submitted work. CP has nothing to disclose. DT has given lectures for Amgen and Sanofi. AB received honoraria for serving in the scientific advisory boards of Almirall, Biogen, Merck and received speaker honoraria from Biogen, Merck, Teva, Bayer, Sanofi-Genzyme, and Novartis; his institution has received research support from Almirall, Biogen, Bayer, Merck, Sanofi-Genzyme, Novartis, Teva, from the Italian Multiple Sclerosis Society, Fondazione Associazione Ricerca Biomedica and San Luigi Onlus.

\section{Funding}

This project was not supported by any specific grants from commercial companies, and there were no conflicts of that kind in either the preparation or support for this manuscript.

\section{Authors' contributions}

GP drafted the manuscript, CP, DT, TBA, DT, DPS, and DM reviewed and improved the manuscript. All authors read and approved the final manuscript.

\section{Acknowledgments}

The authors of the present manuscript participate in the Consortium "Monitoring of monoclonal Antibodies Group in Europe" (MAGE) for inflammatory diseases. The MAGE Consortium is supported by LE STUDIUM Loire Valley Institute for Advanced Studies (http://www.lestudium-ias.com/). 


\section{$\underline{\text { Abstract }}$}

Biopharmaceuticals bring together a number of specific characteristics as compared with other drugs. However, as done for most drugs, an individual adjustment of their dose may be necessary. Similar to "chemical" drugs, biopharmaceuticals used in immuno-inflammatory diseases have a rather narrow therapeutic range, lack good early clinical or biological marker of response, have variable pharmacokinetics, and their serum concentration are most often related with response. Monoclonal antibodies (mAbs) have additional specific sources of pharmacokinetic variability. Low concentrations may increase the risks of immunization, plasmapheresis may increase their elimination, and subcutaneous formulations may be associated with decreased adherence. For all these reasons, pharmacokinetic therapeutic drug monitoring may be useful. However, few randomized controlled TDM studies have been published. For mAbs, a precise definition of the therapeutic concentrations is challenging because of the interindividual variability in their concentration-effect relationship. 


\section{Rationale for TDM of drugs}

Drug monitoring is the process of observing, recording, or detecting the effects of a drug administered to an individual. ${ }^{1}$ Therapeutic drug monitoring (TDM) based on pharmacokinetics uses the concentration of the drug, usually measured in blood, to adjust its dose individually. Its aim is to personalize the dose of the drug according to the pharmacokinetic characteristics of the patient. The interest of TDM for a given drug is studied if this drug fulfills specific criteria. The four main criteria are (1) a narrow therapeutic range with dose-dependent adverse side effects; (2) the lack of good early clinical or biological marker of response allowing to adjust the dose individually; (3) a variability in pharmacokinetics, both between patients and for a given patient, over time; and (4) the observation of relationships between the concentration of drug (or active moieties) and both therapeutic and toxic effects. In addition, TDM may theoretically be useful in specific cases, i.e. (5) when the risk of poor compliance is high; (6) when low concentrations increase the risk of resistance development; or (7) when artificial serum clearance is necessary.

Because TDM allows to reach an effective concentration more rapidly while minimizing drug toxicity, it increases the control of the disease and decreases the need for other treatments. It also limits the use of unnecessary high doses. For these reasons, TDM may lead to lower treatment costs. Since TDM has its own costs, this needs to be confirmed by cost-benefit studies.

\section{Potential interest of TDM for biopharmaceuticals}

\subsection{Similarities with "chemical" drugs}

\section{Narrow therapeutic range}

Biopharmaceuticals may be considered as drugs with a good benefit/risk ratio. However, like "chemical" drugs, they are not devoid of adverse side effects. Besides immunization, the most common adverse effect associated with monoclonal antibodies (mAbs) directed against TNF $\alpha$ (e.g., infliximab), CD20 (e.g., rituximab), or IL-6R (e.g., tocilizumab) is the increased risk of infections. ${ }^{2}$ The risk of infections was found to be related to the dose of anti-TNF $\alpha$ mAbs in some meta-analyses ${ }^{3}$ but not in others. ${ }^{4}$ With rituximab, B-cell depletion may be prolonged, leading to a persistent immunodeficiency. ${ }^{5,6}$

\section{Lack of good clinical or biological marker}

The dose of most drugs needs to be adjusted individually. At the treatment initiation, the recommended dose for intravenous drugs, including biopharmaceuticals, is usually defined according to weight or body surface area. On the other hand, the dose of subcutaneous biopharmaceuticals is often fixed. Afterward, the dose should be adjusted according to patient's therapeutic response or dose-dependent side effects. Although the target-antigen of mAbs is very well known, the blood concentration of the target-antigen is not used as biomarker to monitor the effects of mAbs during the treatment. This may be explained (1) by a lack of proportionality between blood concentration of target-antigen and its total amount in the body, (2) by 
difficulties in measuring the concentration of the target-antigen either because assays do not differentiate its free form and the immune complex or because of its poor stability in blood samples. Therefore, indirect assessments of the target-antigen, using biomarkers such as C-reactive protein for anti-TNF $\alpha$ mAbs or B-cell numeration for anti-CD20 mAbs, may be useful. In multiple sclerosis, pharmacodynamic monitoring of interferon is available. ${ }^{7}$ However, these biomarkers are not always related to the clinical response. Disease activity scores such as DAS28 in rheumatoid arthritis and CDAl in Crohn's disease are commonly used to monitor patients' response to treatment. However, they are not assessed before several weeks of treatment, and most of these indices suffer from subjectivity, either from the patient's own evaluation or from the clinician. In multiple sclerosis, the evaluation occurs even later because it is based on the occurrence of the relapse and/or MRI disease activity. Also, clinical monitoring is complicated by the fact that several end points are used for a given disease, e.g., for Crohn's disease. ${ }^{8}$ Therefore, measurement of blood concentration of the $\mathrm{mAb}$, which reflects the exposure to the drug, appears as a convenient tool of monitoring, available from the first weeks of treatment.

\section{Variability in pharmacokinetics}

The interindividual (between patients) and intraindividual (over time in a given patient) variability in pharmacokinetics of mAbs is well known and was reported for all. ${ }^{9,10}$ This variability is also observed for other biopharmaceuticals such as the fusion protein etanercept ${ }^{11}$ or interferon beta. ${ }^{12}$ Similar to chemical drugs, pharmacokinetics of mAbs used in immuno-inflammatory diseases is significantly influenced by body weight and/or body surface area. ${ }^{13}$ Other sources of variability, more specific to mAbs, are discussed infra.

\section{Concentration-effect relationship}

A relationship between serum concentration and biological and/or clinical responses was reported for most mAbs. This is particularly the case for anti-TNF $\alpha$ such as for infliximab in rheumatoid arthritis, ${ }^{14-18}$ spondyloarthritis, ${ }^{19}$ psoriasis, ${ }^{20,21}$ Crohn's disease ${ }^{22-24}$ and ulcerative colitis. ${ }^{25}$ Regarding adalimumab, a concentrationresponse relationship was reported in rheumatoid arthritis, ${ }^{26,27}$ Crohn's disease, ${ }^{28,29}$ ulcerative colitis, ${ }^{30}$ and psoriasis. ${ }^{31}$ Moreover, such a relationship was reported for other anti-TNF $\alpha$ biopharmaceuticals, such as etanercept ${ }^{11}$ and certolizumab pegol ${ }^{32}$ in rheumatoid arthritis. A concentration-response relationship was reported for $\mathrm{mAbs}$ binding to other target-antigens, such as tocilizumab in rheumatoid arthritis, ${ }^{33,34}$

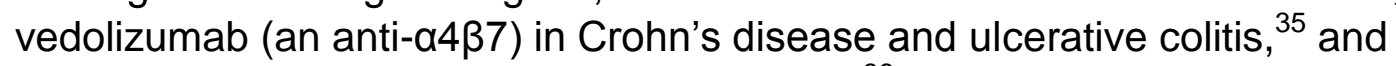
ustekinumab (an anti-IL-12/IL-23) in psoriasis. ${ }^{36}$ In inflammatory arthritis, high infliximab concentrations were recently reported to be correlated with a higher risk of a first serious infectious episode.$^{37}$ Conversely, no concentration-effect relationship was observed for rituximab in rheumatoid arthritis. ${ }^{38}$

\section{Risk of poor compliance}

An increasing number of biopharmaceuticals is administered subcutaneously. This mode of administration may be associated, theoretically, with a risk of decreased 
compliance. ${ }^{39}$ Some publications have already shown that self-administration was a risk factor for discontinuation of mAbs from the own accord of the patient as was a low level of pain ${ }^{40}$ while others found a very good adherence, in psoriasis for instance. $^{41}$

\section{Low concentrations increase the risk of resistance development}

A parallel may be drawn between the risk of resistance development associated with subtherapeutic doses of anti-infectious drugs and the risk of immunization against biopharmaceuticals. Low serum concentrations of infliximab at the treatment initiation were indeed associated with an increased risk of immunization both in rheumatoid arthritis $^{17,42}$ and in ankylosing spondylitis. ${ }^{42}$ Nevertheless, these associations have been only reported for mAbs and at the initiation of the treatment. More studies are therefore needed.

\section{Artificial clearance}

Because of their molecular weight, mAbs are not eliminated during hemodialysis. However, their clearance is increased during plasmapheresis, a therapeutic procedure used to get rid of pathogenic immunoglobulins, with a resulting $40 \%$ decrease in rituximab concentrations in certain patients. ${ }^{43}$ When progressive multifocal leukoencephalopathy, a severe complication of natalizumab, develops, plasmapheresis and immunoadsorption are used for accelerating its clearance. ${ }^{44}$

\subsection{Criteria specific to $m A$ Abs}

Except for weight and body surface area, the sources of interindividual variability in pharmacokinetics of mAbs are mostly different from those of "chemical drugs."

\section{Recycling by FcRn}

As other circulating proteins, mAbs are passively internalized in cells, notably vascular endothelial cells. However, they are protected from degradation in lysosomes by a specific receptor for $\operatorname{lgG}$, the neonatal Fc receptor or FcRn, which recycle them. FcRn protection and recycling explain their long half-life, varying from two to four weeks. Studies reported an influence of a variable number tandem repeat polymorphism of the gene encoding FcRn, FCGRT, on the pharmacokinetics of monoclonal antibodies. ${ }^{45,46}$

\section{Immunization}

Monoclonal antibodies are recombinant proteins, and the risk of immunization is important with mAbs used in immuno-inflammatory diseases. The development of antibodies towards the mAb, usually called anti-drug antibodies (ADA), alters dramatically the pharmacokinetics and leads to a drop in mAb blood concentrations, as shown, e.g., for infliximab, ${ }^{47-51}$ hence loss of response. ${ }^{47,52}$ Many immunogenicity assays, with different characteristics, are available for testing ADA. Monitoring of immunogenicity and the different types of assays are discussed in a short review. ${ }^{53}$

\section{Target-mediated drug disposition}


A part of the clearance of $\mathrm{mAbs}$ is related to their binding to the target-antigen, which may lead to internalization when the target is a membrane receptor or to the formation of immune complexes for circulating targets. The size of these immune complexes is another parameter that influences this clearance. This target-mediated drug disposition (TMDD) is an important source of interindividual and intraindividual pharmacokinetic variability. ${ }^{54}$ The clearance of anti-TNF $\alpha$ mAbs was observed to increase with the level of inflammation in rheumatoid arthritis ${ }^{50}$ and in Crohn's disease. ${ }^{55}$ A study performed in a cohort of patients monitored with the same assay observed that the underlying disease influences infliximab pharmacokinetics. ${ }^{56}$ Another consequence of TMDD is non-linear pharmacokinetics because it is related to the amount of target-antigen. In immuno-inflammatory diseases, this non-linearity is particularly marked for tocilizumab. ${ }^{57}$

\section{Digestive loss in inflammatory bowel disease}

Infliximab is lost into stools of patients with ulcerative colitis and high fecal concentrations of infliximab are associated with the lack of a primary response. ${ }^{58}$

\subsection{Theoretical justification of TDM of biopharmaceuticals}

The characteristics that constitute the basis of TDM of "chemical" drugs are relevant for biopharmaceuticals. In addition, mAbs have specific mechanisms of disposition (notably their recycling by FcRn and TMDD) that may reinforce the interest of TDM. Also, individual dose-adjustment is difficult without TDM because of their long half-life and their non-linear pharmacokinetics. If pharmacoeconomic considerations are taken into account because of the high cost of biopharmaceuticals, TDM could be used to develop drug-sparing strategies.

\section{Levels of evidence for TDM of mAbs}

Although relationships between serum concentrations of biopharmaceuticals and response were reported, few prospective studies analyzed the impact of individual dose adjustment based on drug concentrations on clinical response and outcomes. In a prospective non-comparative study, a significant clinical improvement was observed in rheumatoid arthritis patients in whom an infliximab dose increase was justified by high disease activity and low infliximab concentrations. ${ }^{59}$ The results of controlled studies performed in inflammatory bowel disease are described in a review. ${ }^{60}$ Other short reviews have addressed the level of evidence in rheumatoid arthritis, ${ }^{61}$ spondyloarthritis, ${ }^{62}$ multiple sclerosis, ${ }^{7}$ psoriasis, ${ }^{63}$ and pediatrics. ${ }^{64}$ The need for TDM of belatacept, a fusion protein of the extracellular domain of CTLA4 and the Fc domain of human IgG1, in kidney transplantation was reviewed. ${ }^{65}$ More randomized studies assessing the potential clinical benefits of TDM of biopharmaceuticals are clearly needed.

\section{Study design}

Similar to all clinical trials, TDM studies should include patients who are representative of the treated population. One of the challenges in the design of controlled trials studying the benefit of TDM is the choice of the target concentrations 
of the biopharmaceutical. First, therapeutic concentrations for a given drug may be different in different diseases (e.g., infliximab concentrations predictive of clinical response in rheumatoid arthritis and Crohn's disease are different). Second, therapeutic concentrations for a given drug in a specific disease may be influenced by disease activity. A pharmacokinetic-pharmacodynamic (PK-PD) modeling of adalimumab in rheumatoid arthritis has indeed observed an influence of baseline disease activity, assessed by DAS28, on sensitivity to the mAb, assessed by IC $50 .{ }^{66}$ The target concentration of the mAb should therefore be based on PK-PD modeling ${ }^{67}$ and could be adjusted to individual disease activity.

Pharmaceutical companies should support such studies and assist academic and clinical laboratories setting up external quality assessment schemes for the biopharmaceuticals they commercialize.

\section{$\underline{\text { 5. Conclusion }}$}

Therapeutic mAbs and biopharmaceuticals, in general, are drugs with a complex dose-concentration-effect relationship. The sources of interindividual variability in clinical response are mostly different from those of "chemical" drugs. There are many arguments in favor of a TDM of biopharmaceuticals used in immuno-inflammatory disease, both similar to those relevant to "chemical" drugs and specific for biopharmaceuticals. Randomized controlled studies must be conducted to confirm the theoretical interest of TDM and these need to individually address targetantigens, the different mAbs, and their different indications. 


\section{References}

1. Medline MeSH. Available at:

http://www.ncbi.nlm.nih.gov/mesh/?term=drug+monitoring. Accessed August 2016.

2. Ternant $D$, Bejan-Angoulvant $T$, Passot $C$, et al. Clinical pharmacokinetics and pharmacodynamics of monoclonal antibodies approved to treat rheumatoid arthritis. Clin Pharmacokinet. 2015;54:1107-1123.

3. Singh JA, Cameron C, Noorbaloochi S, et al. Risk of serious infection in biological treatment of patients with rheumatoid arthritis: a systematic review and metaanalysis. Lancet. 2015;386:258-265.

4. Michaud TL, Rho YH, Shamliyan T, et al. The comparative safety of tumor necrosis factor inhibitors in rheumatoid arthritis: a meta-analysis update of 44 trials. Am J Med. 2014;127:1208-1232.

5. Makatsori M, Kiani-Alikhan S, Manson AL, et al. Hypogammaglobulinaemia after rituximab treatment-incidence and outcomes. QJM. 2014;107:821-828.

6. Roberts DM, Jones RB, Smith RM, et al. Rituximab-associated hypogammaglobulinemia: incidence, predictors and outcomes in patients with multisystem autoimmune disease. J Autoimmun. 2015;57:60-65.

7. Caldano M, Raoul W, Rispens T, et al. Therapeutic drug monitoring of biological agents used in the treatment of Multiple Sclerosis. Ther Drug Monit. submitted.

8. Papay $\mathrm{P}$, Ignjatovic $\mathrm{A}$, Karmiris $\mathrm{K}$, et al. Optimising monitoring in the management of Crohn's disease: a physician's perspective. J Crohns Colitis. 2013;7:653-669.

9. Ternant D, Paintaud G. Pharmacokinetics and concentration-effect relationships of therapeutic monoclonal antibodies and fusion proteins. Expert Opin Biol Ther. 2005;5:S37-S47.

10. Oude Munnink TH, Henstra MJ, Segerink LI, et al. Therapeutic drug monitoring of monoclonal antibodies in inflammatory and malignant disease: translating TNF- $\alpha$ experience to oncology. Clin Pharmacol Ther. 2016;99:419-431.

11. Jamnitski A, Krieckaert CL, Nurmohamed MT, et al. Patients non-responding to etanercept obtain lower etanercept concentrations compared with responding patients. Ann Rheum Dis. 2012;71:88-91.

12. Hu X, Cui $Y$, White J, et al. Pharmacokinetics and pharmacodynamics of peginterferon beta-1a in patients with relapsing-remitting multiple sclerosis in the randomized ADVANCE study. Br J Clin Pharmacol. 2015;79:514-522.

13. Bai $\mathrm{S}$, Jorga $\mathrm{K}$, Xin $\mathrm{Y}$, et al. A guide to rational dosing of monoclonal antibodies. Clin Pharmacokinet. 2012;51:119-135.

14. St Clair EW, Wagner CL, Fasanmade AA, et al. The relationship of serum infliximab concentrations to clinical improvement in rheumatoid arthritis: results from ATTRACT, a multicenter, randomized, doubleblind, placebo-controlled trial. Arthritis Rheum. 2002;46:1451-1459. 
15. Mulleman D, Chu Miow Lin D, Ducourau E, et al. Trough infliximab concentrations predict efficacy and sustained control of disease activity in rheumatoid arthritis. Ther Drug Monit. 2010;32:232-236.

16. Wolbink GJ, Voskuyl AE, Lems WF, et al. Relationship between serum trough infliximab levels, pretreatment $C$ reactive protein levels, and clinical response to infliximab treatment in patients with rheumatoid arthritis. Ann Rheum Dis. 2005;64:704-707.

17. Bendtzen K, Geborek P, Svenson M, et al. Individualized monitoring of drug bioavailability and immunogenicity in rheumatoid arthritis patients treated with the tumor necrosis factor alpha inhibitor infliximab. Arthritis Rheum. 2006;54:3782-3789.

18. van den Bemt BJ, den Broeder AA, Wolbink GJ, et al. The combined use of disease activity and infliximab serum trough concentrations for early prediction of (non-)response to infliximab in rheumatoid arthritis. Br J Clin Pharmacol. 2013;76:939-945.

19. Plasencia C, Pascual-Salcedo D, Nuño L, et al. Influence of immunogenicity on the efficacy of long term treatment of spondyloarthritis with infliximab. Ann Rheum Dis. 2012;71:1955-1960.

20. Reich K, Nestle FO, Papp K, et al. EXPRESS study investigators. Infliximab induction and maintenance therapy for moderate-to-severe psoriasis: a phase III, multicentre, double-blind trial. Lancet. 2005;366:1367-1374.

21. Dannepond C, Ternant D, Maruani A, et al. Serum infliximab concentrations and disease activity: a descriptive study of patients with psoriasis. Br J Dermatol. 2016;174:198-200.

22. Maini RN, Breedveld FC, Kalden JR, et al. Therapeutic efficacy of multiple intravenous infusions of anti-tumor necrosis factor alpha monoclonal antibody combined with low-dose weekly methotrexate in rheumatoid arthritis. Arthritis Rheum. 1998;41:1552-1563.

23. Maser EA, Villela R, Silverberg MS, et al. Association of trough serum infliximab to clinical outcome after scheduled maintenance treatment for Crohn's disease. Clin Gastroenterol Hepatol. 2006;4:1248-1254.

24. Cornillie F, Hanauer SB, Diamond RH, et al. Postinduction serum infliximab trough level and decrease of C-reactive protein level are associated with durable sustained response to infliximab: a retrospective analysis of the ACCENT I trial. Gut. 2014;63:1721-1727.

25. Adedokun OJ, Sandborn WJ, Feagan BG, et al. Association between serum concentration of infliximab and efficacy in adult patients with ulcerative colitis. Gastroenterology. 2014;147:1296-1307.

26. Bartelds GM, Wijbrandts CA, Nurmohamed MT, et al. Clinical response to adalimumab: relationship to anti-adalimumab antibodies and serum adalimumab concentrations in rheumatoid arthritis. Ann Rheum Dis. 2007;66:921-926. 
27. Pouw MF, Krieckaert CL, Nurmohamed MT, et al. Key findings towards optimising adalimumab treatment: the concentration-effect curve. Ann Rheum Dis. 2015;74:513-518.

28. Karmiris K, Paintaud G, Noman M, et al. Influence of trough serum levels and immunogenicity on long-term outcome of adalimumab therapy in Crohn's disease. Gastroenterology. 2009;137:1628-1640.

29. Mazor Y, Almog R, Kopylov U, et al. Adalimumab drug and antibody levels as predictors of clinical and laboratory response in patients with Crohn's disease. Aliment Pharmacol Ther. 2014;40:620-628.

30. Baert F, Vande Casteele N, Tops S, et al. Prior response to infliximab and early serum drug concentrations predict effects of adalimumab in ulcerative colitis. Aliment Pharmacol Ther. 2014;40:1324-1332.

31. Menting SP, Coussens E, Pouw MF, et al. Developing a therapeutic range of adalimumab serum concentrations in management of psoriasis: a step toward personalized treatment. JAMA Dermatol. 2015;151:616-622.

32. Lacroix BD, Lovern MR, Stockis A, et al. A pharmacodynamic Markov mixedeffects model for determining the effect of exposure to certolizumab pegol on the ACR20 score in patients with rheumatoid arthritis. Clin Pharmacol Ther. 2009;86:387395.

33. Levi M, Grange S, Frey N. Exposure-response relationship of tocilizumab, an anti-IL-6 receptor monoclonal antibody, in a large population of patients with rheumatoid arthritis. J Clin Pharmacol. 2013;53:151-159.

34. Ohta S, Tsuru T, Terao K, et al. Mechanism-based approach using a biomarker response to evaluate tocilizumab subcutaneous injection in patients with rheumatoid arthritis with an inadequate response to synthetic DMARDs (MATSURI study). J Clin Pharmacol. 2014;54:109-119.

35. Rosario M, Dirks NL, Gastonguay MR, et al. Population pharmacokineticspharmacodynamics of vedolizumab in patients with ulcerative colitis and Crohn's disease. Aliment Pharmacol Ther. 2015;42:188-202.

36. Papp KA, Langley RG, Lebwohl M, et al. Efficacy and safety of ustekinumab, a human interleukin-12/23 monoclonal antibody, in patients with psoriasis: 52 -week results from a randomised, double-blind, placebo-controlled trial (PHOENIX 2). Lancet. 2008;371:1675-1684.

37. Bejan-Angoulvant T, Ternant D, Daoued F, et al. Brief report: relationship between serum infliximab concentrations and risk of infections in patients treated for spondyloarthritis. Arthritis Rheum. 2017;69:108-113.

38. Thurlings $\mathrm{RM}$, Teng $\mathrm{O}$, Vos $\mathrm{K}$, et al. Clinical response, pharmacokinetics, development of human anti-chimaeric antibodies, and synovial tissue response to rituximab treatment in patients with rheumatoid arthritis. Ann Rheum Dis.

2010;69:409-412. 
39. Deleu D, Alsharoqi I, Al Jumah MA, et al. Will new injection devices for interferon $\beta-1$ a s.c. affect treatment adherence in patients with multiple sclerosis? An expert opinion in the Middle East. Int J Neurosci. 2011;121:171-175.

40. Betegnie AL, Gauchet A, Lehmann A, et al. Why do patients with chronic inflammatory rheumatic diseases discontinue their biologics? An assessment of patients' adherence using a self-report questionnaire. J Rheumatol. 2016;43:724730 .

41. Hsu Y, Gniadecki R. Patient adherence to biologic agents in psoriasis. Dermatology. 2016;232:326-333.

42. Ducourau E, Mulleman D, Paintaud G, et al. Antibodies toward infliximab are associated with low infliximab concentration at treatment initiation and poor infliximab maintenance in rheumatic diseases. Arthritis Res Ther. 2011;13:R105.

43. Azzopardi N, François M, Laurent E, et al. Influence of plasma exchange on rituximab pharmacokinetics. Br J Clin Pharmacol. 2013;76:486-488.

44. Vennegoor A, Rispens T, Van Oosten BW, et al. Application of serum natalizumab levels during plasma exchange in MS patients with progressive multifocal leukoencephalopathy. Mult Scler. 2015;21:481-484.

45. Passot C, Azzopardi N, Renault S, et al. Influence of FCGRT gene polymorphisms on pharmacokinetics of therapeutic antibodies. Mabs. 2013;5:614619.

46. Caulet $\mathrm{M}$, Lecomte $\mathrm{T}$, Bouché $\mathrm{O}$, et al. Bevacizumab pharmacokinetics influence overall and progression-free survival in metastatic colorectal cancer patients. Clin Pharmacokinet. 2016;55:1381-1394.

47. Baert $F$, Noman $M$, Vermeire $S$, et al. Influence of immunogenicity on the longterm efficacy of infliximab in Crohn's disease. N Engl J Med. 2003;348:601-608.

48. Hu C, Xu Z, Zhang Y, et al. Population approach for exposure-response modeling of golimumab in patients with rheumatoid arthritis. J Clin Pharmacol. 2011;51:639648.

49. Pascual-Salcedo D, Plasencia C, Ramiro S, et al. Influence of immunogenicity on the efficacy of long-term treatment with infliximab in rheumatoid arthritis.

Rheumatology (Oxford). 2011;50:1445-1452.

50. Ternant D, Ducourau E, Perdriger A, et al. Relationship between inflammation and infliximab pharmacokinetics in rheumatoid arthritis. Br J Clin Pharmacol. 2014;78:118-128.

51. Ternant $D$, Karmiris $K$, Vermeire $S$, et al. Pharmacokinetics of adalimumab in Crohn's disease. Eur J Clin Pharmacol. 2015;71:1155-1157.

52. Wolbink GJ, Vis M, Lems W, et al. Development of antiinfliximab antibodies and relationship to clinical response in patients with rheumatoid arthritis. Arthritis Rheum. 2006;54:711-715. 
53. Bloem K, Hernández B, Martínez Feito A, et al. Immunogenicity of therapeutic antibodies: monitoring anti-drug antibodies in a clinical context. Ther Drug Monit. submitted.

54. Gibiansky L, Gibiansky E. Target-mediated drug disposition model: relationships with indirect response models and application to population PK-PD analysis. $J$ Pharmacokinet Pharmacodyn. 2009;36:341-351.

55. Ternant D, Berkane Z, Picon L, et al. Assessment of the influence of inflammation and FCGR3A genotype on infliximab pharmacokinetics and time to relapse in patients with Crohn's disease. Clin Pharmacokinet. 2015;54:551-562.

56. Passot $C$, Mulleman $D$, Bejan-Angoulvant $T$, et al. The underlying inflammatory chronic disease influences infliximab pharmacokinetics. MAbs. 2016;8:1407-1416.

57. Frey N, Grange S, Woodworth T. Population pharmacokinetic analysis of tocilizumab in patients with rheumatoid arthritis. J Clin Pharmacol. 2010;50:754-766.

58. Brandse JF, van den Brink GR, Wildenberg ME, et al. Loss of infliximab into feces is associated with lack of response to therapy in patients with severe ulcerative colitis. Gastroenterology. 2015;149:350-355.

59. Mulleman D, Méric JC, Paintaud G, et al. Infliximab concentration monitoring improves the control of disease activity in rheumatoid arthritis. Arthritis Res Ther. 2009;11:R178.

60. Detrez I, Van Stappen T, Arranz MD, et al. Current practice for therapeutic drug monitoring of biopharmaceuticals in inflammatory bowel disease. Ther Drug Monit. submitted.

61. Medina F, Plasencia C, Goupille P, et al. Therapeutic drug monitoring of biopharmaceuticals in rheumatoid arthritis. Ther Drug Monit. submitted.

62. Medina F, Placensia C, Goupille P, et al. Therapeutic drug monitoring of biopharmaceuticals in spondyloarthritis. Ther Drug Monit. submitted.

63. Hermans $C$, Harrans $P$, Segaert $S$, et al. Current practice of therapeutic drug monitoring of biopharmaceuticals in psoriasis patients. Ther Drug Monit. submitted.

64. Murias S, Magallares L, Albizuri F, et al. TDM of biopharmaceuticals in Paediatrics. Ther Drug Monit. submitted.

65. de Graav GN, Bergan S, Baan CC, et al. Therapeutic drug monitoring of belatacept in kidney transplantation. Ther Drug Monit. 2015;37:560-567.

66. Ducourau E, Ternant D, Lequerre T, et al. Towards an individualised target concentration of adalimumab in rheumatoid arthritis. Ann Rheum Dis. 2014;73:14281429.

67. Passot C, Pouw M, Mulleman D, et al. Therapeutic drug monitoring of biologicals will benefit of pharmacokinetic and pharmacokinetic-pharmacodynamic modelling. Ther Drug Monit. submitted. 